\title{
ANALISIS KERUSAKAN POROS GENERATOR PEMBANGKIT LISTRIK DAMAGE ANAL YSIS OF A POWER GENERATOR SHAFT
}

\author{
Soedardjo, SA ${ }^{\text {a) }}$, Bambang Purnomo $Y^{\text {b) }}$ \\ a) Pusat Teknologi Reaktor dan Keselamatan Nuklir - BATAN \\ Kawasan PUSPIPTEK Gd. 80 Serpong, Tangerang 15314 \\ ${ }^{b)}$ Balai Besar Teknologi Kekuatan Struktur - BPPT \\ Kawasan PUSPIPTEK Gd. 220 Serpong, Tangerang 15314 \\ e-mail : soedardjobatan@yahoo.com, bbpurnomo61@gmail.com
}

Tanggal masuk naskah : 18/07/2014; Tanggal revisi: 19/09/2014 ; Tanggal persetujuan cetak : 08/10/2014

\begin{abstract}
Abstrak
Telah dianalisis kerusakan beberapa poros dari suatu generator pembangkit listrik. Latar belakang analisis ini adalah seringnya terjadi poros generator pembangkit listrik di Indonesia yang patah. Tujuan dari analisis adalah untuk mengetahui penyebab kerusakan poros generator pembangkit listrik. Metodologi yang digunakan antara lain wawancara dengan pemilik dan karyawan di lokasi, pemeriksaan visual di situs, pemeriksaan visual di bengkel, uji kekerasan di bengkel, komposisi kimia di laboratorium dan analisis berdasarkan beberapa referensi. Hasil Analisis yang diperoleh adalah: poros generator nomor $1 \mathrm{~A}$ patah karena terjadi kelebihan beban putaran, poros nomor $1 B$ retak melingkar di daerah fillet, poros nomor 2 retak yang berorientasi pada sudut sekitar $45^{\circ}$ terhadap sumbu poros. Kesimpulan yang dapat diambil, poros generator pembangkit listrik patah karena desain fillet sebagai sumber tegangan yang tidak sempurna, beban berlebihan, dan material mengalami patah ulet.
\end{abstract}

Kata Kunci : poros, pembangkit listrik,uji kekerasan,komposisi kimia

\begin{abstract}
The damage shafts of a power generator have analyzed. The background of this analysis is the shaft generators for electricity in Indonesia frequently are broken. The purpose of the analysis is to determine the cause of damage to the shaft generators. Methodologies used include interviews with the owners and employees at the site, visual inspection on site, visual inspection at the workshop, the workshop hardness testing, chemical composition in the laboratory and analysis based on several references. Analysis of the results obtained are: generator shaft number $1 A$ fracture due to rotation overload, shaft number $1 B$ is cracked circular in the fillet, shaft number 2 cracks oriented at an angle of about $45^{\circ}$ to the axis of the shaft. The conclusion that can be taken, power generator shaft fractures due to the design of the fillets as a stress concentration is not perfect, excessive loads, and occurred material ductile fracture.
\end{abstract}

Keywords : Shaft, power generator, hardness testing, chemical composation 


\section{PENDAHULUAN.}

Analisis kerusakan beberapa poros dari suatu generator pembangkit listrik ini dilakukan pada tahun 2011, bekerjasama dengan beberapa Pemerintah Daerah yang mempunyai PLTD. Latar belakang analisis bermula dari peristiwa kecelakaan nuklir yang berdampak pajanan radiasi mencapai INES 7 seperti PLTN Fukushima Dai Ichi, antara lain disebabkan pembangkit listrik cadangan berupa generator pembangkit listrik tidak beroperasi secara normal, karena dilanda bencana tsunami. Dari peristiwa tersebut terjadi station blackout - loss of all alternative power (SBO). Pada dasarnya. desain keselamatan pada generator juga masuk dalam kategori kelas-1 (kelas tertinggi dalam standar keselamatan PLTN). Namun, desain tersebut memiliki persyaratan tinggi gelombang tsunami sebesar 5.7 meter. Dan kenyataan tsunami terjadi lebih dari 15 meter, sehingga air masuk ke ruang generator dalam PLTN Fukushima-1 [1]. Untuk itu perlu dilakukan beberapa simulasi kerusakan-kerusakan yang mungkin terjadi dari berbagai generator pembangkit listrik.

Tujuan analisis poros generator pembangkit listrik ini, adalah apa akar masalah penyebab poros atau poros generator pembangkit listrik tersebut, berkali-kali mengalami retak hingga patah?

Metoda yang digunakan antara lain pengumpulan data operasi dan peristiwa kerusakan poros melalui wawancara dengan pemilik dan karyawan yang mengoperasikan generator tersebut, pemeriksaan visual poros di lapangan, pemeriksaan visual poros di bengkel, uji kekerasan poros di bengkel, komposisi kimia poros di laboratorium, dan analisis berdasarkan beberapa referensi [2 - 4].

\section{BAHAN DAN METODA}

Poros generator pembangkit listrik sering mendapat beban berupa tegangan, torsi, kompresi, bending, atau kombinasi dari semuanya. Poros juga kadang-kadang mengalami tekanan getaran. Dalam hal ini, poros dibebani oleh gabungan tegangan tarik, tekan dan atau torsi. Selain itu poros biasanya patah pada daerah yang mengalami konsentrasi tegangan seperti pada daerah fillet.

Fillet adalah daerah lekukan perubahan diameter poros yang besar dengan diameter poros yang kecil. Konsentrasi tegangan tersebut dapat mengurangi ketahanan lelah secara efektif. Jika ada tegangan secara metalurgi di daerah fillet yang dapat disebabkan karena terjadi retak akibat peristiwa quench, lubang korosi, kotoran inklusi bukan dari logam, rapuh karena ada partikel asing sehingga logam tidak homogen, cacat las, dan lain-lain, maka akan mempercepat poros patah saat dioperasikan [5].

Dari Gambar 1. Ditunjukkan berbagai rancangan fillet yang dapat mengurangi pembesaran terjadinya tegangan berlebih.

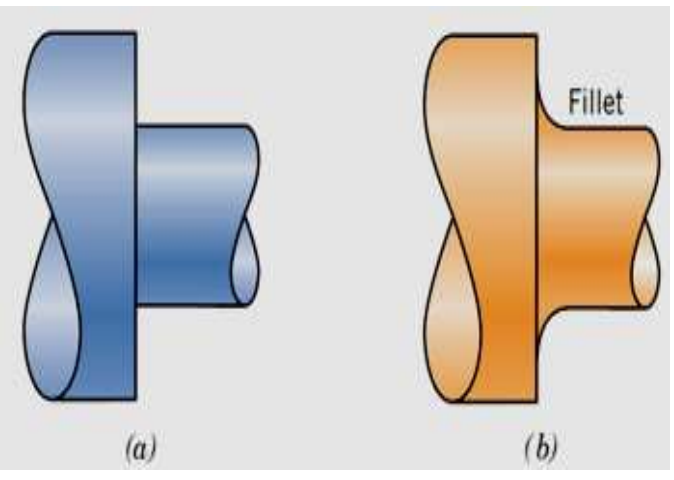

Gambar 1 : Geometri sudut-sudut fillet

Dari Gambar 1 (a) Rancangan fillet yang buruk dengan sudut yang tajam dan (b) adalah rancangan fillet yang baik dengan sudut yang tumpul, sehingga diharapkan poros akan dapat beroperasi lebih lama, karena konsentrasi tegangannya berkurang pada daerah diameter poros yang mengalami perubahan diameter. Perubahan diameter poros diperlukan, adalah untuk menghindari gerakan memanjang searah sumbu poros, saat poros diputar. Hal tersebut, gerakan poros akan ditahan oleh rumah-rumahan poros atau disebut dengan bearing. Untuk menghindari kegagalan kelelahan (failure fatigue), dilakukan dengan mengatur desain radius fillet, missal yang semula bersudut tajam tegak lurus menjadi bersudut lengkung atau landai.

Pada kegagalan stres rendah atau rotasi lentur, arah rotasi dapat dilihat melalui tanda-tanda perubahan distorsi. Tegangan yang tinggi pada seluruh bagian luar dari poros, mulai menyebabkan kegagalan untuk di banyak lokasi. Tegangan total tinggi ini hanya mungkin merupakan hasil dari beban pada bagian atau mungkin disebabkan oleh konsentrasi 
tegangan tinggi yang bekerja pada beban sedang atau rendah.

Pada penampang patahan poros, ada alur-alur yang berbentuk garis-garis bintang sebagai batas pertemuan dua arah penjalaran alur patahan di sekitar pinggir diameter poros yang disebut Ratchet Marks, seperti terlihat pada Gambar 2.

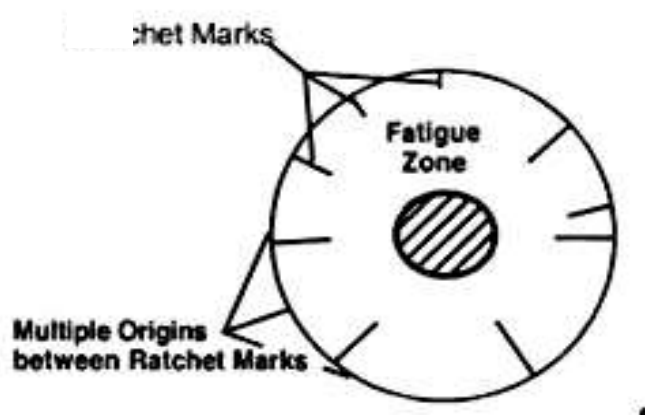

Gambar 2 : Titik-titik asal terjadinya patahan antara tanda-tanda Rachet dan daerah lelah.

Dari Gambar 2, tanda Ratchet yang menunjukkan batas antara dua sumber kegagalan retak yang berdekatan dan dapat bersinggunqan dan bertemu satu dengan yang lain, seperti ditunjukkan pada Gambar 3. Terlihat bahwa ada dua sumber retak, dan tanda Ratchet ada di antara kedua sumber retak. Adanya tanda Ratchet menunjukkan asal-usul dari sumber konsentrasi tegangan yang relatif tinggi.

Dengan melihat kedua sumber tanda Ratchet dan luasnya, maka pada umumnya dapat dipahami asal sumber konsentrasi tegangan yang menjadi penyebab utama fraktur. Sebagai contoh, kombinasi dari tanda Ratchet yang banyak sekali dan zona tanda Ratchet kecil-kecil, menunjukkan bahwa beban terasa ringan, tapi ada konsentrasi tegangan tinggi. Selain itu, dengan melihat tepi tanda Ratchet, seseorang dapat mengatakan apakah beban putar juga andil sebagai penyebab kegagalan.

Jika ketegangan telah menyebabkan kegagalan, sisi tanda Ratchet biasanya tegak lurus ke penampang patahan. Jika beban utama yang menyebabkan kegagalan adalah beban akibat putaran, maka sisi tanda Ratchet akan meruncing.

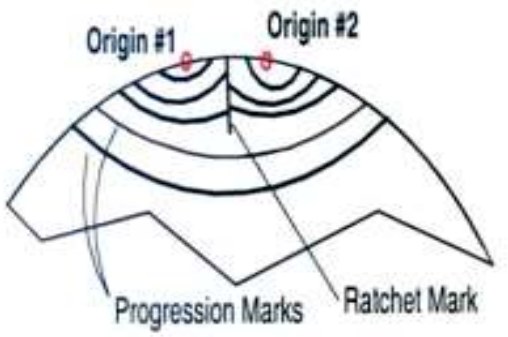

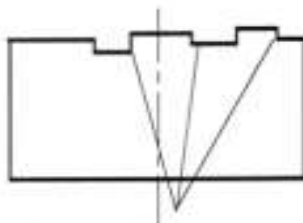

Side view of ratchet marks caused by tension or bending

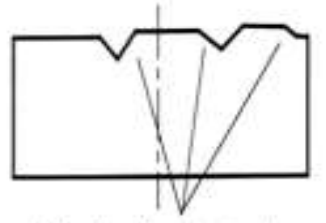

Side view of ratchet marks where the major force was torsion
Gambar 3 : Sumber-sumber retak dari berbagai sumber tanda Ratchet [6].

Untuk mengetahui lebih tepat patahnya poros diakibatkan oleh tegangan sederhana, torsi atau beban kompresi, maka dibuatlah diagram orientasi tegangan normal dan tegangan geser dalam poros dan perilaku fraktur tunggal yang besar dari bahan ulet dan rapuh seperti yang tertera di Gambar 4.

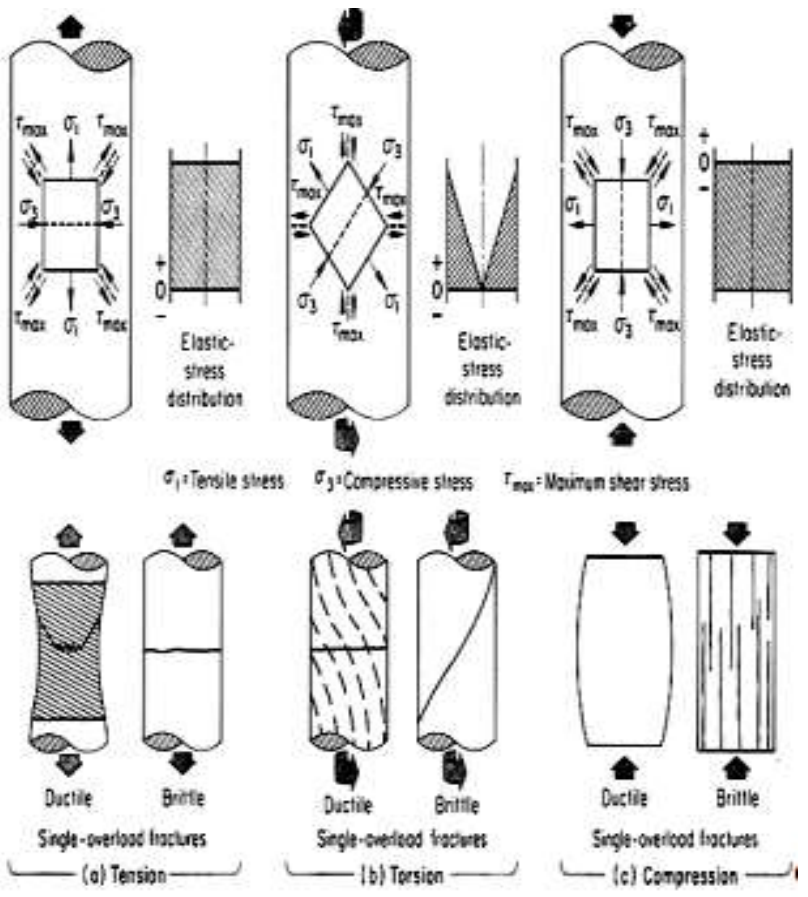

Gambar 4 : Diagram orientasi tegangan normal dan tegangan geser dalam poros dan perilaku fraktur tunggal yang besar dari bahan ulet dan rapuh.

Keterangan Gambar 4:(a)akibat ketegangan sederhana.(b) akibat torsi. (c) akibat beban kompresi. 


\section{HASIL DAN PEMBAHASAN}

Dari hasil wawancara pekerja di lapangan didapat informasi bahwa: ada ketidak stabilan putaran poros, karena beban dari generator sering berubah, seperti ada gangguan jaringan di luar generator pembangkit listrik, yang mengakibatkan putaran generator dapat naik dan turun secara tiba-tiba. Kerusakan poros dapat diakibatkan karena kedudukan poros naik turun atau misalignment, adanya getaran pada poros. Dari hasil wawancara pernah terjadi wadah generator pernah mengalami panas berlebihan hingga disemprot air. Untuk itu para operator generator harus mengawasi kondisi generator setiap saat dan dihindari jangan sampai ketiduran.

Poros Generator nomor 1 telah diganti dua kali disebabkan oleh terjadinya retak. Poros Generator nomor 2 telah diganti sekali karena terjadi retak juga. Generator yang dianalisis adalah fabrikan dari Niigata Jepang, type $8 \mathrm{~L}$ dengan kapasitas 2,8 MW dan $6 \mathrm{~L}$ dengan kapasitas 2,8 MW. Poros-poros tersebut adalah hasil pembuatan kembali (rebuilding) sekitar 2 (dua) tahun yang lalu (tahun 2010). Setelah poros baru hasil rebuild tersebut dioperasikan secara penuh selama 2 (dua) bulan, maka poros tersebut mengalami kegagalan berupa retak.Dari wawancara dengan operator atau pemilik poros generator, diperoleh data material yang terbuat dari AISI 1040 Baja.

\subsection{Uji Visual}

Dari uji visual di lapangan diperoleh data bahwa poros nomor 1 berasal dari generator nomor 1 dan poros nomor 2 berasal dari generator nomor 2. Karena poros nomor 1 retak, diganti dengan poros baru dinamakan poros $1 \mathrm{~A}$ ditunjukkan pada Gambar 5.

Poros nomor $1 \mathrm{~A}$ telah patah dan diprediksi karena beban putar. kekuatan bahan poros $1 \mathrm{~A}$ diprediksi lebih lemah dari beban putar yang harus dipikul oleh poros tersebut, dan pola patahannya dapat dilihat pada Gambar 5. Poros nomor 1A tersebut, patah di daerah fillet yang dirancang dengan sudut fillet terlalu tajam mendekati sudut $90^{\circ}$. Padapermukaan patahan ada pola-pola bintang sekeliling diameter fillet, yang menandakan bahwa patahan mengalami distorsi pada bagian tertentu atau poros mengalami kegagalan karena putaran yang ulet.

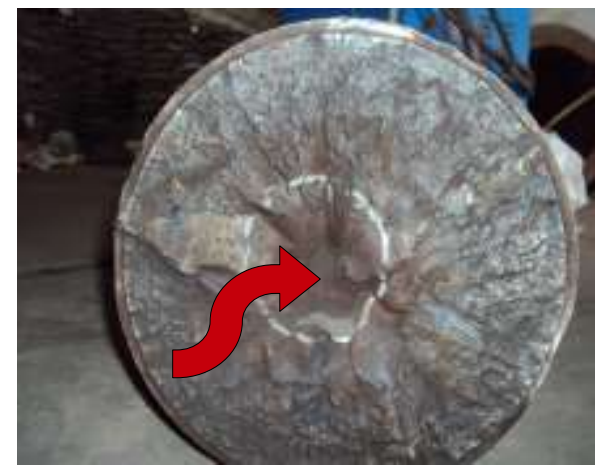

Gambar 5 : Poros Generator nomor $1 \mathrm{~A}$ yang patah karena putaran.

Karena poros nomor $1 \mathrm{~A}$ setelah dioperasikan selama beberapa bulan mengalami patah, maka poros baru yang mengganti poros $1 \mathrm{~A}$ dinamakan poros 1B ditunjukkan pada Gambar 6. Dari Gambar 6 , retak melingkar tidak menyudut tersebut adalah retak putar yang ulet. Berdasarkan Gambar 3, poros nomor 1A terlihat gagal karena putaran dengan tegangan yang rendah, tetapi konsentrasi tegangan dalam kondisi tinggi, karena bentuk fillet-nya tajam atau tidak tumpul.

Pada Poros nomor 1B telah mengalami retak secara melingkar pada diameter poros pada daerah fillet, seperti terlihat pada Gambar 7. Karena retaknya pada daerah fillet maka dapat diambil kesimpulan daerah fillet tersebut sebagai sumber konsentrasi tegangan yang dapat merusak poros.

Retak biasanya terjadi di wilayah fillet. Itu berarti "wilayah fillet adalah sumber konsentrasi tegangan". Contoh dari konsentrasi tegangan yang berat adalah fillet dengan radius kecil di pertemuan perubahan diameter suatu poros. Biasanya fillet menghasilkan kontur permukaan patahan yang cembung di dekat sisi diameter pros yang lebih kecil.

Jika sumber konsentrasi tegangan yang berupa fillet lebih tajam dan menyebabkan diskontinuitas yang disebabkan semakin kecil jari-jari kelengkungan, maka konsentrasi tegangan akan lebih parah. Probabilitas kegagalan lelah (fatigue) dapat dikurangi misalnya dengan membuat rancangan modifikasi, dimana perubahan kontur tiba-tiba mengarah ke sudut tajam dieliminasi, atau membuat bentuk fillet yang jari-jari kelengkungannya besar pada titik di mana 
ada perubahan diameter untuk poros berputar (Gambar 1).

Pada poros generator nomor 2 telah mengalami retak secara diagonal miring sekitar $45^{\circ}$ yang berawal dari daerah fillet, seperti terlihat pada Gambar 8 Poros tersebut mengalami retak rapuh. Hal tersebut dikarenakan bahan logam poros terlalu rapuh atau jika terbebani secara ekstrem cepat atau tiba-tiba pada arah tegak lurus bagian yang ulet. Beban kejut yang sangat berat pada bagian paling ulet dapat menyebabkan poros mengalami patah seperti patah tulang rapuh.

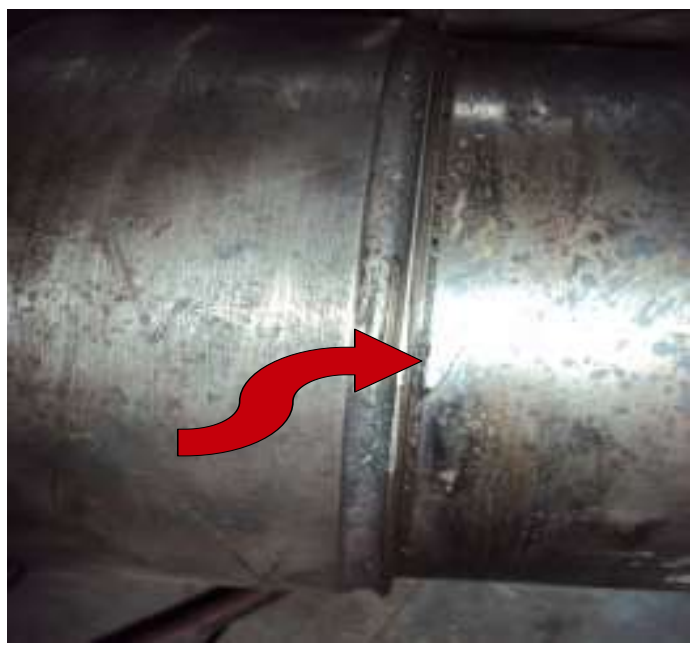

Gambar 7 : Poros Generator 1B yang retak melingkar pada daerah fillet.

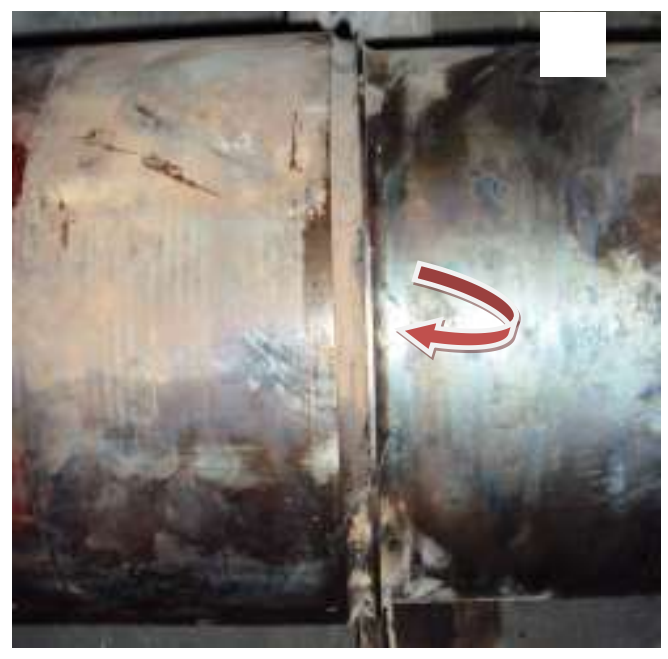

Gambar 8 : Poros generator nomor 2 retaksecara diagonal miring sekitar $45^{\circ}$ yang berawal dari daerah fillet.

Dari Gambar 8. bahwa poros nomor 2, yang terjadi retak miring dengan orientasi pada sudut sekitar $45^{\circ}$ terhadap sumbu poros, hal tersebut menunjukkan bahwa retak yang terjadi disebabkan oleh tegangan tarik normal pada generator, bersudut $45^{\circ}$ terhadap bidang datar, karena pengaruh retak ketegangan tunggal yang berlebihan dan bahannya adalah bahan yang rapuh.

\subsection{Uji Kekerasan}

Berdasarkan situs Matweb, untuk material AISI 1040, mempunyai kekerasan Vickers sebesar 155 HV [7]

Hasil uji pengujian kekerasan untuk poros 1B ditunjukkan pada Gambar 9.

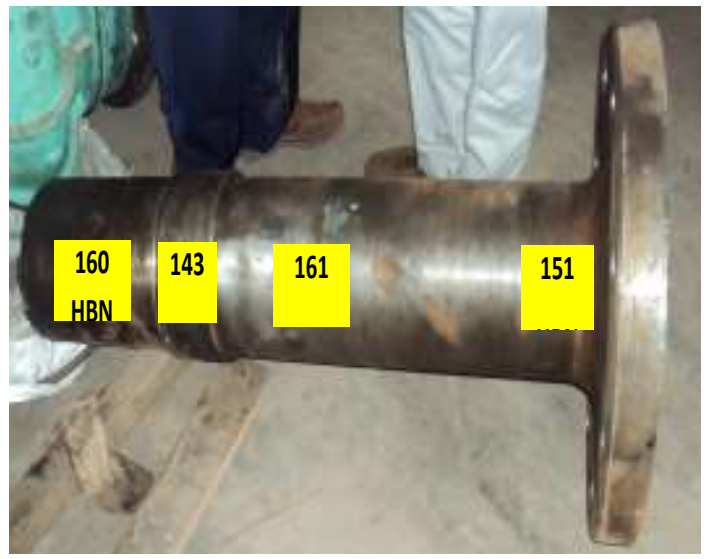

Gambar $9:$ Kekerasan untuk poros nomor 1B

Hasil Uji Kekerasan pada poros nomor 2 ditunjukkan pada Gambar 10.

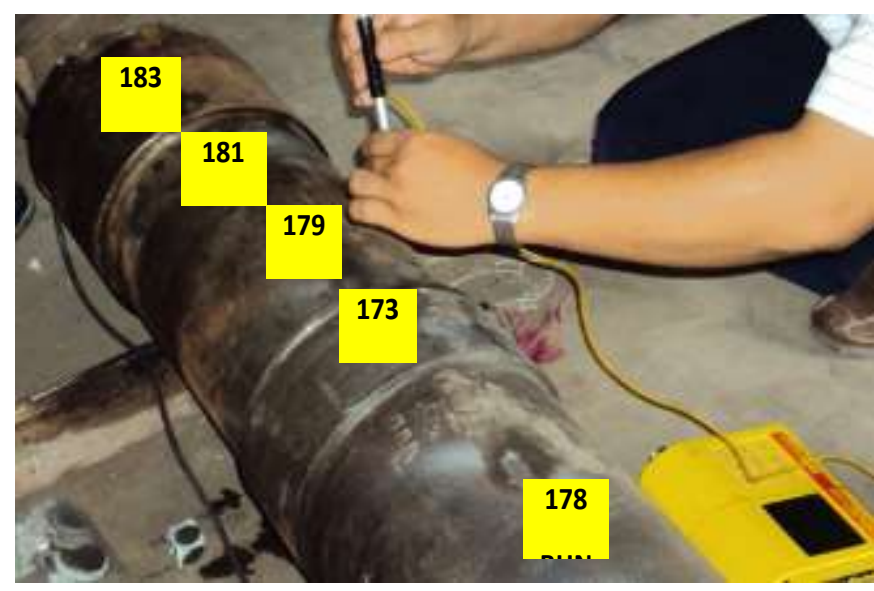

Gambar 10 : Kekerasan untuk poros nomor 2

$\begin{array}{ccc}\text { Dari hasil pengujian } & \text { kekerasan, } \\ \text { terlihat bahan tidak mengalami }\end{array}$ 
pengerasan terlebih dahulu sebelum dipakai. Sehingga kekuatan bahan akan sangat lemah untuk memikul beban kerja dari generator.

\subsection{Uji Komposisi Kimia}

Komposisi Kimia untuk material AISI 1040 berdasarkan situs Matweb, mempunyai karakteristik Carbon: 0.37 $0.44 \%$, Manganese 0.6 - $0.9 \%$, Phosphorus 0.04 max, Sulphur 0.05 max.

Hasil uji komposisi Kimia poros generator nomor.1B ditunjukkan pada Gambar 11 dan untuk poros generator nomor.2 seperti ditunjukkan pada Gambar 12. Bahan poros generator nomor 1B lebih lemah dari Poros generator nomor 2 berdasarkan komposisi karbon ( C ) dan Mangaan (Mn).

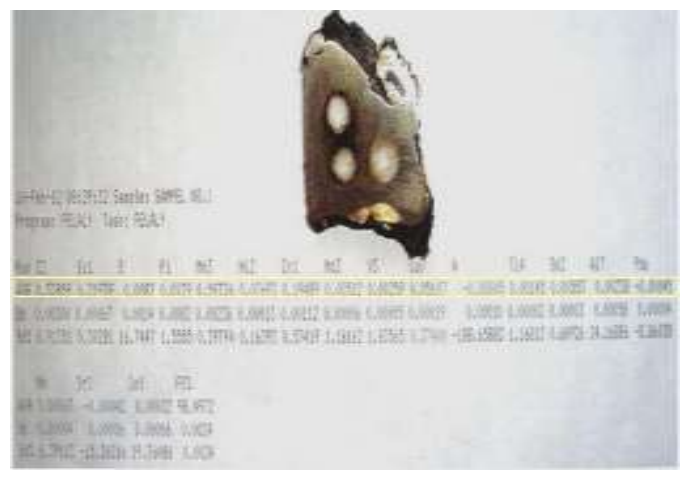

Gambar 11 : Komposisi Kimia poros generator nomor 1.

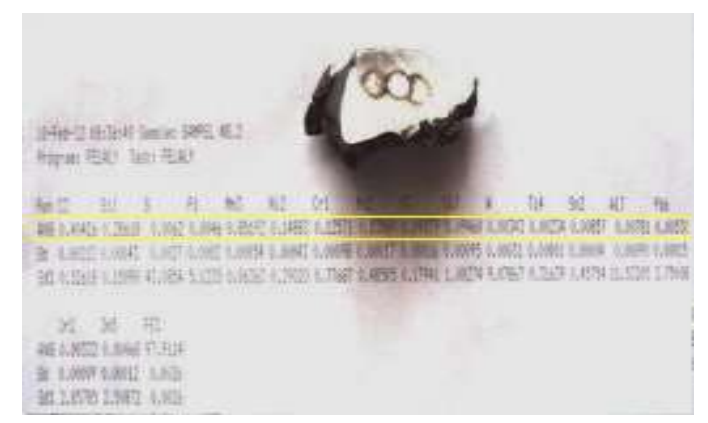

Gambar 12 : Komposisi Kimia poros generator nomor 2.

Hasil analisis secara keseluruhan adalah poros generator pembangkit listrik yang difabrikasi oleh Niigata Jepang pada tahun 1978, dan dibangun kembali (rebuild) oleh jasa rebuilding lokal Indonesia atau tingkat Asia. Poros Generator yang baru di rebuild, menunjukkan bukti adanya retak pada daerah fillet, setelah beroperasi sekitar 2 bulan untuk beberapa poros Generator 1 dan Generator 2.

Beberapa kendala untuk melakukan analisis kerusakan tersebut, adalah data manufaktur terutama bahan desain tidak tersedia. Obyek poros generator telah dipindah dari situs ke bengkel oleh yang mempunyai (owner) generator, sehingga keakuratan investigasi dilakukan setelah ada campur tangan dari pihak pemilik poros generator, yang dapat menjadikan hasil analisis kurang akurat. Akibatnya, hasil analisis kerusakan ini hanya dapat dilakukan berdasarkan teknik dan aspek ilmiah tanpa membandingkan dengan sertifikat rancangan fabrikasi, operasi dan pemeliharaan dari fabrikan Niigata Jepang.

\section{KESIMPULAN}

Penyebab kerusakan poros generator pembangkit listrik untuk poros generator nomor $1 \mathrm{~A}$ yang patah, karena terjadi kelebihan beban putaran, yang dapat diketahui melalui penampang lintang patahan yang berpola garis-garis bintang (Rachet). Dengan demikian patahnya poros tersebut disebabkan oleh patah ulet atau disebabkan oleh kelebihan beban di daerah fillet sebagai sumber konsentrasi tegangan tinggi. Penyebab kerusakan poros generator nomor $1 \mathrm{~B}$ yang berupa retak melingkar di daerah fillet, karena fillet merupakan sumber konsentrasi tegangan.

$$
\text { Penyebab kerusakan poros }
$$

generator nomor 2 yang berupa retak berorientasi sudut sekitar $45^{\circ}$ terhadap sumbu poros, hal tersebut menunjukkan bahwa retak yang terjadi disebabkan oleh tegangan tarik normal pada generator dengan arah sudut $45^{\circ}$ karena pengaruh beban retak tegangan tunggal yang berlebihan dan material yang digunakan dalam kondisi rapuh. Perlu menghitung ulang rancangan pembuatan poros generator nomor 1 dan 2. Poros generator pada saat fabrikasi sebaiknya dilakukan perlakuan panas seperti pendinginan cepat (quenched, tempered), sehingga diperoleh struktur mikro yang mengakibatkan bahan lebih kuat yang dapat dideteksi melalu uji kekerasannya. Jari-jari fillet dibuat lebih tumpul dari rancangan fillet sebelumnya, sehingga fillet tidak terlalu menjadi konsentrasi tegangan yang berlebihan. Perlu perlakuan shot peening didaerah fillet setelah setelah dilakukan permesinan saat membuat fillet, agar tegangan-tekan sisa 
pada permukaan dapat dikurangi, yang akan menghambat pembentukan retak karena pengaruh kelelahan dan meningkatkan ketahanan kelelahan.

\section{DAFTAR PUSTAKA}

1. HIDA, "Kecelakaan PLTN di Jepang (7), Overview Kecelakaan PLTN Fukushima, Japan Atomic Power Co (JAPC)", Pusat Teknologi Reaktor dan Keselamatan Nuklir, Gd. 80 Kawasan Puspiptek Serpong Tangerang, Copyright @PTRKNBATAN 2010 All rights reserved.Powered by MetNet, http://www.batan.go.id/ptrkn/index. php?option=com_content\&task=view \&id=173\&ltemid=1;

2. ANONYMOUS, , Scientific equipment and supplies for use in materials analysis, http://www.matweb.com/search/Da taSheet.aspx?MatGUID=689e75eb19f 4417a93c3a8da240a7d4e;

3. ANONYMOUS, "Failure Analysis and Prevention", was published in 2002 as Volume 11 of the ASM Handbook. Copyright (C) 2002, By ASM International;

4. ANONYMOUS, "The Shock and Vibration", Digest 2004; 36; 287, DOI: $10.1177 / 0583102404045439$, (C) 2004 SAGE Publications; http://svd.sagepub.com/cgi/conten t/abstract/36/4/287,
5. KEN YOUSSEFI, MAE DEPT, SJSU, "Fatigue Failure », Copyright (C) 2012 Scribd Inc, http://www.scribd.com/doc/785149 91/Fatigue-Failure;

6. N.W. SACHS, P.E., "Fracture Feature, Understanding the Surface Features of Fatigue Fractures: How They Describe the Failure Cause and the Failure History", Journal of Failure Analysis and Prevention Volume 5(2) April 2005, http://www.asminternational.org/pdf /spotlights/jfap0502p011.pdf,

7. ANONYMOUS, MATERIAL WEB, "AISI 1040 Steel, annealed at $790^{\circ} \mathrm{C}$ (1450 F)", Copyright 1996-2012 by MatWeb,LLC,

http://www.matweb.com/search/Da taSheet.aspx?MatGUID=689e75eb19f 4417a93c3a8da240a7d4e.

8. W. R. Warke, "Failure Analysis And Prevention", Stress-Corrosion Cracking, ASM Handbook, Vol.9, 1810. 2010

9. Colangelo and Heiser, "Analysis of Metalurgical Failures", Jhon Wiley \& Son Inc, New York, p1-2.81-84. 2010

10. Bruce L. Bramfitt, "Carbon And Alloys Steel", Handbook of Materials Selection Edited by Myer Kutz, JOHN Wiley \& Sons inc, New York, p 32 - 36, 2009

11. ...."Metallography and Microstructures", ASM Handbook, Vol.9, 2435, 2686,2009 